\title{
Floração, frutificação e maturação de frutos de morangueiro cultivados em ambiente protegido ${ }^{1}$
}

\author{
Odirce Teixeira Antunes²; Eunice Oliveira Calvete ${ }^{3}$; Hélio Carlos Rocha ${ }^{3}$; Alexandre Augusto Nienow ${ }^{3}$; \\ Franciele Mariani ${ }^{3}$; Cristiane de Lima Wesp ${ }^{3}$
}

${ }^{2}$ Escola Agrotécnica Federal de Sertão, C. Postal 21, 99170000 Sertão-RS; ${ }^{3 U P F-F A M V, ~ C . ~ P o s t a l ~ 611, ~ 99001-970 ~ P a s s o ~ F u n d o-R S ; ~ E-~}$ mail: odirce@eafsertao.gov.br; calveteu@upf.br

\section{RESUMO}

Determinou-se o número de dias para a ocorrência e a duração dos estádios fenológicos de morangueiro, bem como o período de floração, frutificação e maturação dos frutos das cvs. Oso Grande, Tudla, Chandler e Dover. O trabalho foi executado no interior de uma estrutura galvanizada de $510 \mathrm{~m}^{2}$ (estufa plástica), em Passo Fundo-RS, em 2003 e 2004. A primeira etapa constou da avaliação das datas de ocorrência e da duração dos estádios fenológicos das quatro cultivares de morangueiro, em um experimento fatorial (cultivares $\mathrm{x}$ estádios fenológicos) com delineamento inteiramente casualizados, em cinco repetições. Na segunda etapa, determinouse o número de dias até o início da floração (50\% da área em floração) e da formação de frutos ( $10 \%$ dos frutos maiores que $2,5 \mathrm{~cm}$ de comprimento), início e final da colheita. Os nove estádios fenológicos foram determinados pela seguinte escala: $1=$ aparecimento do botão floral; $2=$ aparecimento das pétalas; $3=$ flores completamente abertas; $4=$ pétalas secas e caídas; $5=$ formação do fruto; $6=$ aumento do tamanho do fruto; $7=$ fruto com sementes visíveis no receptáculo; $8=$ começo da maturação, com maioria dos frutos brancos; $9=$ frutos maduros com 75 a $100 \%$ da superfície vermelha. A duração dos nove estágios variou de 36,4 dias para a cv, Tudla a 40 dias para a cv. Oso Grande. O estádio 4, caracterizado pela queda das pétalas foi o mais longo para todas as cultivares, com 11,3 dias, em média. Para a cultivar Dover, além dessa fase, também o estádio 6 foi o mais prolongado. Considerando o início do florescimento e da frutificação, a cultivar Dover foi a mais precoce, quando comparada com as demais cultivares.

Palavras-chave: Fragaria X ananassa Duch.,frutificação, graus-dia.

\begin{abstract}
Blooming, fruit set, and fruit maturation of strawberry growing in protected environment

The duration time of phenological stages, blooming, fruit set, and maturation periods of strawberry cultivars Oso Grande, Tudla, Chandler, and Dover were evaluated. The study was carried out in a 510 m2 plastic greenhouse, in Passo Fundo- RS, Brazil, in 2003 and 2004. A completely randomized experimental design with five replicates was used in a factorial scheme (cultivars $\mathrm{x}$ phenological stages). In the first step of the experiment, both the dates and the duration time of phenological stages were evaluated. In the second step, the number of the days up to the blooming (50\% of the area), the fruit formation (10\% of the fruit higher than $2.5 \mathrm{~cm} \mathrm{long}$ ), and the date of beginning and end of harvesting was evaluated. The scale used for the phenological stages were : $1=$ beginning of the flowerbud stage; $2=$ beginning of petals ; $3=$ blooming; $4=$ drying and falling of petals; $5=$ fruit formation; $6=$ fruit elongation; $7=$ fruit receptacle with visible seeds; $8=$ beginning of maturation, with most of fruits having white colour; $9=$ mature fruits with 75 to $100 \%$ of the surface with red colour. The duration of the nine phenological stages ranged from 36.4 days for cv. Tudla to 40 days for cv. Oso Grande. Stage 4 was the longest stage (11.3 days). In all four cultivars, For cv. Dover, stage 6 was longer as stage 4 . Considering the duration time between blooming and fruit set, cv. Dover, was considesed the most precocious.
\end{abstract}

Keywords: Fragaria X ananassa Duch., fruit growing, degree-days.

(Recebido para publicação em 13 de outubro de 2005; aceito em 14 de novembro de 2006)

$\mathrm{O}$ morangueiro (Fragaria X ananassa Duch.), pertencente à família Rosaceae, é uma planta rasteira, propagada vegetativamente por estolhos. A tecnologia de cultivo é mais avançada em países como Estados Unidos, Espanha, Japão, Itália, Coréia do Sul e Polônia (Resende et al., 1999). No Brasil, os principais estados produtores são Minas Gerais, São Paulo, Rio Grande do Sul, Paraná, Santa Catarina, Espírito Santo, Distrito Federal e Goiás. A produtividade e a qualidade dos frutos do morangueiro é muito influenciada pe- los elementos micrometeorológicos e pelas práticas de manejo. Conseqüentemente, cultivares de morangueiro diferem de acordo com a adaptação regional, fazendo com que uma cultivar que se desenvolve satisfatoriamente em uma região não apresente o mesmo desempenho em outro local com condições ambientais diferentes (Ueno, 2004).

Uma planta, para atingir o estádio reprodutivo, passa por uma série de transformações entre os estádios de desenvolvimento. Na etapa vegetativa, os meristemas apicais, por sua atividade mitótica, seguida dos processos de elongação celular e diferenciação, determinam os pontos de crescimento vegetativo e, em seu conjunto, formam os diferentes tecidos e órgãos da planta. Já na floração (etapa reprodutiva) ocorre a diferenciação do meristema vegetativo para o floral, originando os componentes da flor (pétalas, estames e pistilo), ao invés dos órgãos vegetativos (folhas, caule e estolhos) (Duarte Filho et al., 1999). Segundo os mesmos autores, as diferenças entre as fases de desenvolvimento são bem visíveis no 
morangueiro. No cultivo para produção de frutos, a fase vegetativa é verificada logo após o transplante das mudas, realizado de fevereiro a junho, de acordo com a região.

O florescimento e a frutificação do morangueiro, que ocorrem nas gemas, dependem de uma série de processos fisiológicos. Esses quatro processos compreendem a indução, iniciação, diferenciação e antese (Verdial, 2004). A iniciação da flor é caracterizada por mudanças físicas e químicas que ocorrem na gema, a partir de estímulos florais detectados pelas folhas. No período de transição para a floração, o ápice do sistema caulinar vegetativo é transformado em reprodutivo. A diferenciação da flor é o desenvolvimento dos órgãos florais dentro do botão. A antese caracteriza a fase final do processo de florescimento, quando os órgãos florais são expostos, possibilitando a polinização e, conseqüentemente, a fertilização (Guttridge, 1985). A diferenciação das gemas depende de fatores genéticos e ambientais. Entre os vários fatores ambientais, o comprimento do dia e a temperatura estão envolvidos na indução floral (Galletta \& Bringhurst, 1989 apud Verdial, 2004). Bueno et al. (2002) observaram que o potencial de florescimento do morangueiro é afetado por fatores internos, pela temperatura, pelo fotoperíodo, ou pelos três fatores conjuntamente. Porém, esta sensibilidade varia de acordo com as cultivares. Para o florescimento em cultivares não reflorescentes, as condições ambientais favoráveis que deverão ser observadas são dias curtos (inferior a 14 horas de luz/dia) e temperaturas baixas (menor que $15^{\circ} \mathrm{C}$ ).

No morangueiro, as inflorescências possuem número variável de flores, que se formam a partir das gemas existentes nas axilas das folhas. A primeira flor normalmente origina o primeiro fruto, em geral o mais desenvolvido da planta. Depois dessa flor, os botões laterais vão se abrindo um a um, acompanhando o desenvolvimento da cimeira. A ramificação da inflorescência pode ser basal, resultando em mais de um talo de flor aparente, originando uma flor terminal acompanhada por flores secundárias e terciárias (Brazanti, 1989). Os "frutos" desenvolvem-se a partir de carpelos soltos de uma mesma flor, possuindo eixo do receptáculo carnoso-sucoso, vermelho, frutíolos drupóides, afundados no receptáculo denominados "frutos múltiplos". São forma- dos por muitos ovários amadurecidos, pertencentes à uma inflorescência, que crescem juntos, formando uma infrutescência. Frutos múltiplos são um conjunto de frutos simples, que podem ser identificados individualmente, de acordo com suas características (Barroso et al., 1999).

Méier (1994) relatou que o morangueiro pode apresentar nove estádios fenológicos durante todo o seu ciclo. Embora existam algumas informações sobre a fenologia da floração e maturação dos frutos do morangueiro, é necessário identificar o seu comportamento no local do cultivo. Esse conhecimento é importante para programas de melhoramento genético, bem como para o manejo da cultura. A determinação está condicionada à soma térmica do local, expressa em graus-dia, referindo-se a diferença entre o acúmulo da temperatura média diária e a temperatura-base, acima da qual a planta consegue realizar suas funções fisiológicas (Carvalho et al., 2005). Para as cultivares de morangueiro, estima-se que a temperatura-base é de $70^{\circ} \mathrm{C}$. Segundo Cunha (1997), as normais climatológicas de Passo Fundo são as seguintes: temperatura média anual $17,5^{\circ} \mathrm{C}$; média das mínimas de $13,2^{\circ} \mathrm{C}$; média das máximas de $23,6^{\circ} \mathrm{C}$; precipitação média anual de 1.787 $\mathrm{mm}$; média anual da umidade relativa do ar de $72 \%$; média anual de horas de frio com temperaturas $\leq 7,0^{\circ} \mathrm{C}$ de $422 \mathrm{~h}$, variando de $214 \mathrm{~h}$ a $554 \mathrm{~h}$. Mota (1992) relata acúmulos de frio de $375 \mathrm{~h}$ (maio a agosto) e $420 \mathrm{~h} \leq$ (maio a setembro).

O objetivo deste trabalho foi determinar o número de dias para a ocorrência e a duração dos estádios fenológicos da floração e frutificação do morangueiro, bem como identificar o período de floração, frutificação e maturação dos frutos, em cultivo protegido, no município de Passo Fundo-RS.

\section{MATERIAL E MÉTODOS}

O trabalho foi conduzido no interior de uma estrutura (tipo "arco") galvanizada de $510 \mathrm{~m}^{2}$ (51 x 10,0 m), com teto semicircular, com pé direito de $3,5 \mathrm{~m}$, tendo a maior altura 4,6 m, coberta com filme de polietileno de baixa densidade (PEBD), com aditivo anti-ultravioleta e espessura de $150 \mu \mathrm{M}$.

Para acompanhamento do ciclo da cultura, foram utilizadas plantas de morangueiro das cultivares Oso Grande,
Tudla, Chandler e Dover. O trabalho constou de duas etapas. A primeira constou da determinação do número de dias de ocorrência e da duração dos diferentes estádios fenológicos da floração e frutificação em quatro cultivares de morangueiro. Para efeito de análise estatística os tratamentos constaram de um fatorial (cultivares $\mathrm{x}$ estádios fenológicos) dispostos em um delineamento inteiramente casualizados, em cinco repetições. O período de observações se estendeu de 03/09/2003 a 20/ 10/2003. Nesse ano as plantas de morangueiro foram transplantadas no dia $05 / 05$. Os resultados referentes a essa etapa foram submetidos a análise de variância e as diferenças entre médias comparadas pelo teste de Tukey a 5\% de probabilidade. A temperatura média compensada e a umidade relativa do ar foram determinadas segundo metodologia descrita por Nienow (1997), e registrados diariamente através de termohigrógrafo da marca Sato modelo NS-II-Q, instalados no interior da estufa e na parte externa, a uma altura de 1,20 $\mathrm{m}$. (Figura 1 ).

$\mathrm{Na}$ segunda etapa do experimento foram determinados o número de dias até o início da floração e a formação de frutos, o início e o final da colheita. $\mathrm{O}$ início da floração foi considerado quando $50 \%$ das plantas, dentro da parcela, apresentavam pelo menos uma flor aberta por planta. O início da formação de frutos foi identificado quando $10 \%$ das plantas existentes na parcela apresentavam pelo menos um fruto por planta, com no mínimo $2,5 \mathrm{~cm}$ de comprimento. Considerou-se na maturação os frutos que apresentaram $75 \%$ de coloração vermelha na epiderme. Para determinar a soma térmica, para cada estádio fenológico, foram calculados os grausdia, considerando a diferença entre a temperatura base de $7^{\circ} \mathrm{C}$ e as temperaturas médias diárias no interior da estufa. O período das avaliações da segunda etapa foi de 05/05/2003 a 23/12/2003 e de 06/05/2004 a 20/12/2004. Em 2004, as plantas de morangueiro foram transplantadas no dia 06/05.

A escala atribuída para os nove estádios fenológicos foi baseada em Meier (1994) e modificada para determinar a floração, frutificação e maturação dos frutos de morangueiro, segundo a seguinte classificação: a) estádio 1: aparecimento do botão floral, na base da 
A)

Tํ e UR (iméida compensada 2003)

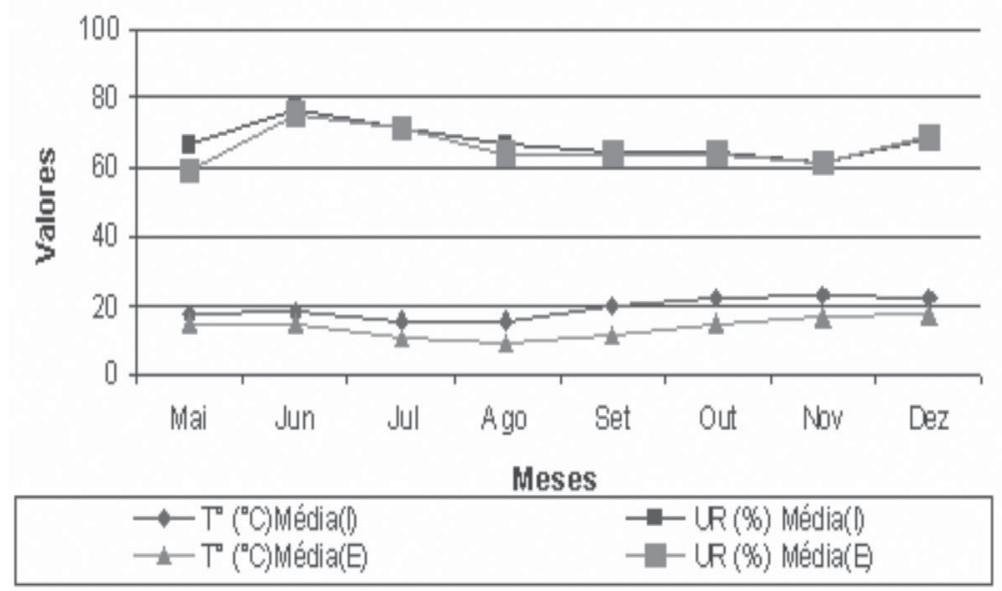

B)

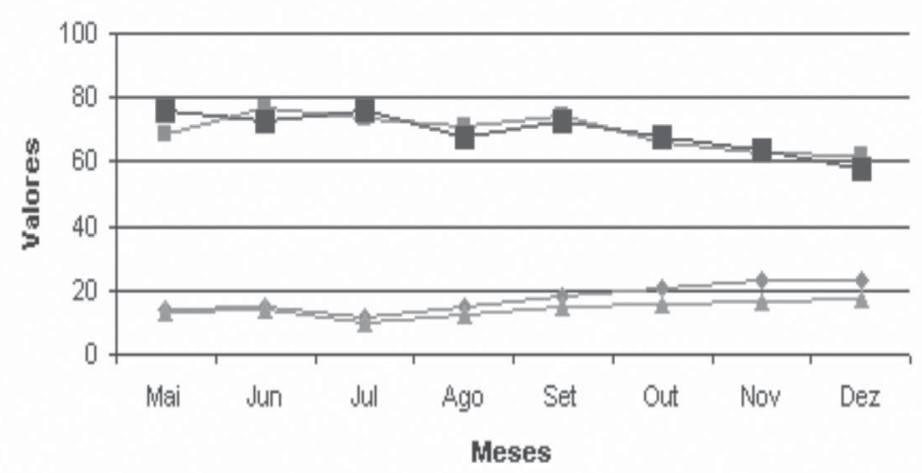

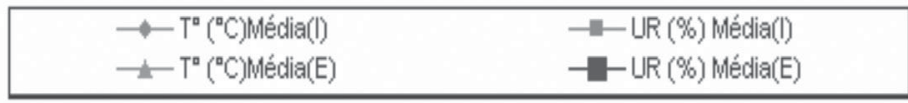

Figura 1.Temperatura $\left({ }^{\circ} \mathrm{C}\right)$ e umidade relativa do ar $(\%)$ do ambiente interno e externo da estufa, no período maio a dezembro de 2003 (A) e maio a dezembro 2004 (B). Passo FundoRS, UPF, 2004.

Tabela 1. Duração (dias) dos nove estádios fenológicos durante a floração, frutificação e maturação dos frutos de quatro cultivares de morangueiro. Passo Fundo-RS, UPF, 2003.

\begin{tabular}{lcccl}
\hline Estádios & \multicolumn{4}{c}{ Duração (dias) } \\
\cline { 2 - 5 } fenológicos $^{1}$ & Oso Grande & Tudla & Chandler & Dover \\
\hline 1 & $4,4 \mathrm{Ab}$ & $3,4 \mathrm{Ab}$ & $5,2 \mathrm{Aab}$ & $3,0 \mathrm{Ab}$ \\
2 & $1,8 \mathrm{Ab}$ & $2,0 \mathrm{Ab}$ & $1,6 \mathrm{Ab}$ & $1,8 \mathrm{Ab}$ \\
3 & $3,0 \mathrm{Ab}$ & $5,8 \mathrm{Ab}$ & $5,0 \mathrm{Aab}$ & $4,4 \mathrm{Aab}$ \\
4 & $17,4 \mathrm{Aa}$ & $10,0 \mathrm{Ba}$ & $8,4 \mathrm{Ba}$ & $9,2 \mathrm{Ba}$ \\
5 & $2,4 \mathrm{Ab}$ & $5,2 \mathrm{Aab}$ & $3,6 \mathrm{Aab}$ & $5,4 \mathrm{Aab}$ \\
6 & $2,2 \mathrm{Bb}$ & $3,4 \mathrm{Bb}$ & $5,6 \mathrm{ABab}$ & $9,2 \mathrm{Aa}$ \\
7 & $3,4 \mathrm{Ab}$ & $2,6 \mathrm{Ab}$ & $3,4 \mathrm{Ab}$ & $2,0 \mathrm{Ab}$ \\
8 & $2,2 \mathrm{Ab}$ & $1,6 \mathrm{Ab}$ & $2,2 \mathrm{Ab}$ & $1,4 \mathrm{Ab}$ \\
9 & $3,2 \mathrm{Ab}$ & $2,8 \mathrm{Ab}$ & $2,8 \mathrm{Ab}$ & $2,4 \mathrm{Ab}$ \\
\hline
\end{tabular}

1Estádios fenológicos 1= Aparecimento do botão floral; $2=$ Aparecimento das pétalas (estádio de balão); $3=$ Flores completamente abertas; $4=$ Pétalas secam e caem; 5= Formação do fruto; $6=$ Aumento do tamanho do fruto; $7=$ Fruto com percepção das sementes no receptáculo; 8= Começo da maturação, maioria dos frutos brancos; $9=$ frutos maduros com 75 a $100 \%$ da superfície vermelha; Médias seguidas da mesma letra maiúscula na linha e da mesma letra minúscula na coluna, não diferem entre si pelo teste de Tukey ( $p$ d" 0,05 ). roseta foliar, gemas floríferas com aspecto globoso e de coloração esverdeada; b) estádio 2: aparecimento das pétalas (estádio de balão); c) estádio 3: flores primárias, secundárias e terciárias completamente abertas; d) estádio 4: as pétalas secam e caem; e) estádio 5: formação do fruto com o receptáculo sobressalente da coroa das sépalas; f) estádio 6: aumento do tamanho do fruto pelo alongamento celular; g) estádio 7: fruto aumentando de tamanho com percepção das sementes no tecido do receptáculo; h) estádio 8: começo da maturação, maioria dos frutos brancos; i) estádio 9: frutos maduros apresentando $75 \%$ a $100 \%$ da superfície vermelha.

\section{RESULTADOS E DISCUSSÃO}

O comportamento das quatro cultivares de morangueiro avaliadas foi semelhante em quase todos os estádios fenológicos, apenas diferindo nas fases 4 e 6 (Tabela 1). A fase em que o botão floral pôde ser observado, denominouse de estádio 1 (Figura 2). Neste estádio as gemas floríferas têm aspecto globoso e de coloração esverdeada. As cultivares permaneceram, em média, quatro dias, nesse estádio (Tabela 1). A cv. Chandler levou 5,2 dias e a cv. Dover três dias, até atingirem o estádio 2. Esta fase corresponde ao aparecimento das pétalas, embora se encontrassem ainda fechadas (estádio de balão). Dentre todos os estádios, este foi o mais curto, com cerca de 1,8 dias, apenas diferindo do estádio 4 nas cvs. Oso Grande, Tudla e Chandler, e na cv. Dover do estádio 4 e 6 . O estádio 3 se estendeu, em média, por 4,5 dias. Esse estádio foi caracterizado pelas flores completamente abertas. Nesta fase ocorre a polinização, ou seja, os estigmas estão receptivos para receberem o grão de pólen de outra flor. Ao atingirem o estádio 4, as pétalas secaram e caíram, independente se as flores estavam ou não polinizadas. O estádio 4 foi o que mais se prolongou em todas as cultivares, com aproximadamente 17,4 dias na cv. Oso Grande e 8,4 dias na cv. Chandler. Já na cv. Dover a maior duração foi observada nos estádios 4 e 6 (Tabela 1). A formação de um pequeno "fruto múltiplo" foi observado no estádio 5, levando em média 4,2 dias até atingir o estádio 6. Nesta fase, ocorre o alongamento celular, permitin- 


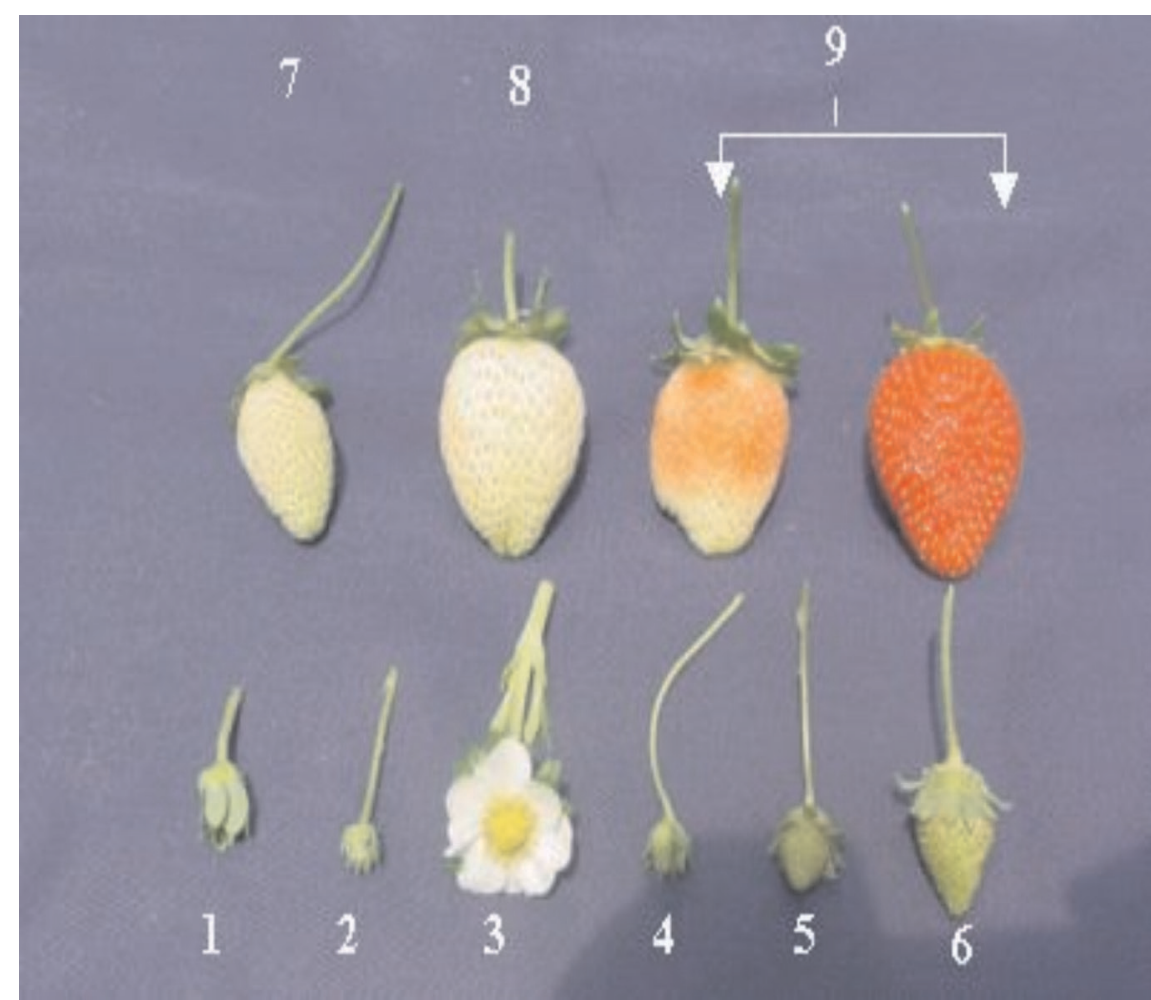

Figura 2. Estádios fenológicos (1 a 9) da floração; frutificação e maturação dos frutos de quatro cultivares de morangueiro. Passo Fundo-RS, UPF, 2003.

Tabela 2. Número de dias e soma térmica em graus-dia para o início da floração e frutificação, e início e término da colheita em quatro cultivares de morangueiro cultivados em ambiente protegido. Passo Fundo-RS, UPF, 2003-2004.

\begin{tabular}{|c|c|c|c|c|c|c|c|c|}
\hline \multirow[t]{2}{*}{ Cultivares } & \multicolumn{2}{|c|}{$\begin{array}{c}\text { Início de floração } \\
\Sigma \text { térmica* }\end{array}$} & \multicolumn{2}{|c|}{$\begin{array}{c}\text { Início frutific. } \Sigma \\
\text { térmica } \\
\end{array}$} & \multicolumn{2}{|c|}{$\begin{array}{c}\text { Início colheita } \Sigma \\
\text { térmica }\end{array}$} & \multicolumn{2}{|c|}{$\begin{array}{l}\text { Término colheita } \\
\Sigma \text { térmica }\end{array}$} \\
\hline & 2003 & 2004 & 2003 & 2004 & 2003 & 2004 & 2003 & 2004 \\
\hline Dover & 493 & 162 & 921 & 419 & 1007 & 442 & 3037 & 2294 \\
\hline Chandler & 622 & 236 & 1007 & 518 & 1045 & 577 & 3037 & 2294 \\
\hline O. Grande & 622 & 259 & 978 & 518 & 1045 & 577 & 3037 & 2294 \\
\hline Tudla & 622 & 224 & 1007 & 518 & 1045 & 577 & 3037 & 2294 \\
\hline \multirow[t]{2}{*}{ Cultivares } & \multicolumn{2}{|c|}{$\begin{array}{c}\text { Início de } \\
\text { floração }\left(\text { dias }^{\star \star}\right)\end{array}$} & \multicolumn{2}{|c|}{$\begin{array}{l}\text { Início frutific. } \\
\text { (dias) }\end{array}$} & \multicolumn{2}{|c|}{$\begin{array}{l}\text { Início colheita } \\
\text { (dias) }\end{array}$} & \multicolumn{2}{|c|}{$\begin{array}{l}\text { Término colheita } \\
\text { (dias) }\end{array}$} \\
\hline & 2003 & 2004 & 2003 & 2004 & 2003 & 2004 & 2003 & 2004 \\
\hline Dover & 44 & 36 & 87 & 75 & 98 & 83 & 232 & 224 \\
\hline Chandler & 56 & 45 & 98 & 98 & 102 & 104 & 232 & 224 \\
\hline O. Grande & 56 & 47 & 93 & 98 & 102 & 104 & 232 & 224 \\
\hline Tudla & 56 & 44 & 98 & 98 & 102 & 104 & 232 & 224 \\
\hline
\end{tabular}

*Soma térmica em graus-dias; **Dias após o transplante.

do o aumento do tamanho do "fruto múltiplo". As cultivares apresentaram uma amplitude de duração neste período entre 2,2 dias, na cv. Oso Grande, até 9,2 dias na cv. Dover. No estádio 7 os "frutos múltiplos" aumentaram de tamanho, em resultado do alongamento celular. A variação observada nesta fase entre as cultivares foi pequena, atingin- to múltiplo" do morangueiro é classificado como fruto não climatérico, portanto, deve ser colhido no ponto correto de maturação, ou seja, quando estiver com $75 \%$ de coloração vermelha na epiderme. Considerando o período entre o início do estádio 1 e o final do estádio 9, obteve-se uma média de 38,4 dias. A cultivar Tudla completou os nove estádios em 36,4 dias e a cv. Oso Grande em 40 dias.

Quanto à floração, a cv. Dover demonstrou ser a mais precoce, pois aos 44 dias após o transplante, em 2003, e aos 36 dias, em 2004, teve início o florescimento. Esta precocidade, em relação às demais, também foi observado no início da frutificação e colheita, nos dois anos (Tabela 2). Estes dados confirmam observações de Bueno et al. (2002), quando estudaram o florescimento de 17 cultivares de morangueiro em São Bento de Sapucaí-SP. Neste estudo, os autores realizaram uma classificação em grupos, referente ao início do florescimento, em que a cv. Dover foi classificada no grupo I, dos mais precoces (60 - 64 dias), cv. Oso Grande no grupo II (65 - 70 dias) e a cv. Chandler no grupo III (> 70 dias até o início do florescimento).

No ano de 2004, todas as cultivares iniciaram o período de florescimento mais cedo que em 2003 (Tabela 2). Na cv. Dover esta antecipação foi de 8 dias, enquanto na cv. Tudla foi de 12 dias. Entretanto, tomando como base a soma térmica, no ano de 2004, foram inferiores a 2003, o que provavelmente favoreceu a antecipação no início da floração em todas as cultivares. Entretanto, apenas a cv. Dover teve o início da frutificação antecipada em relação ao ano de 2003.

Desta forma, analisando os estádios fenológicos dessas quatro cultivares de morangueiro, conclui-se que a fase da antese, caracterizada no estádio três, teve a duração média de 4,5 dias. O estádio quatro foi o mais longo para as cvs. Oso Grande, Tudla e Chandler. Para a cv. Dover, as fases quatro e seis foram as mais prolongadas. Quanto o início do florescimento, da frutificação e da colheita, a cv. Dover foi a mais precoce. 


\section{REFERÊNCIAS}

BARROSO GM; MORIN MP; PEIXOTO AL; ICHASO CLF. 1999. Frutos e sementesMorfologia aplicada à sistemática de dicotiledôneas. Viçosa: UFV. 443p.

BRAZANTI EC.1989. La fresa. Madri: Mundiprensa. 386p.

BUENO SCS; MAIAAHN; TESSARIOLI NETO J. 2002. Florescimento de 17 cultivares de morangueiro (Fragaria $\mathrm{X}$ ananassa Duch.), em São Bento do Sapucaí-São Paulo. In: CONGRESSO BRASILEIRO DE FRUTICULTURA, 17. Anais... Belém: SBF.(CD-ROM).

CARVALHO SLC de; NEVES CSVJ; BÜRKLE R; MARUR CJ. 2005. Épocas de indução floral e soma térmica do período do florescimento à colheita de abacaxi 'Smooth Cayenne'. Revista Brasileira de Fruticultura 27:430-433.

CUNHA GR. 1997. Meteorologia: fatos e mitos. Passo Fundo: Embrapa-CNPT. 268p.
DUARTE FILHO J; CUNHA RJP; ALVARENGA DA; PEREIRA GE; ANTUNES LEC. 1999. Aspectos do florescimento e técnicas empregadas objetivando a produção precoce em morangueiros. Informe Agropecuário 20: 3035.

GUTTRIDGE CG. 1985. Fragaria x ananassa. In: HALVEY AH (editor). CRC handbook of flowering. Boca Raton: CRC Press. p. 16-33.

MEIER U.1994. Codificación BBCH de los estádios fenológicos de desarrollo de la fresa. Disponível em http://www.bba.de/veroeff/ bbchspa.pdf. Acessado em 14 de abril de 2005.

MOTAFS da. 1992. Mapeamento de horas de frio para indicação do cultivo de frutíferas briófilas no Rio Grande do Sul. Revista Brasileira de Fruticultura 14: 83-88.

NEVES FILHO L de C. 2002. Alguns pontos na comercialização de frutas e hortaliças. Revista Frutas \& Legumes 14:12-16.
NIENOW AA. 1997. Comportamneto morfológico, fenológico e produtivo de cultivares de pessegueiro (Prunus pérsica L. Batsch),submetidos à épocas de poda de renovação após colheita na região de Jaboticabal-SP. Jaboticabal: UNESP.170p (Tese doutorado).

RESENDE LM de A; MASCARENHAS MHT; PAIVA BM. 1999. Programa de produção e comercialização de morango. Informe Agropecuário 20:5-19.

UENO B. 2004. Manejo integrado de doenças do morango. In: SIMPÓSIO NACIONAL DO MORANGO, 2. Anais... Pelotas: Embrapa Clima Temperado. p. 69-77.

VERDIAL MF. 2004. Frigoconservação e vernalização de mudas de morangueiro (Fragaria X ananassa Duch.) produzidas em sistema de vasos suspensos. Piracicaba: ESALQ. 71p (Tese de doutorado). 